http://dx.doi.org/10.12795/PH.1992.v07.i01.17

\title{
EL MARQUES D'OLINCOURT O LA ALTERIDAD COMO DEFENSA DEL YO EN UN RELATO DEL MARQUES DE SADE
}

\author{
Magdalena Padilla García
}

\begin{abstract}
The various ways in which Sade made use of his character, the Marquis of Olincourt (Le président mystifié), as his perfect double are analysed. He profitc by him in order to defend himself from the accusations and sentences he was under, and make a harsh attack on justice and religion at the same time, as well as to criticize the reality of his time, within the critical

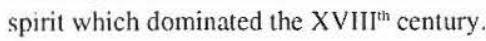

A lo largo de estas páginas nos proponemos realizar un estudio de un personaje del marqués de Sade: el marqués d'Olincourt, utilizado por el autor para defenderse de las acusaciones de las que fue objeto y que llevaron al escritor a la deshonra personal y familar. Intencionalidad por otra parte, que nos aparece ya manifestada en el propio título de la obra (Le Président mystifié) como veremos más adelante.

Concluido el relato, el autor nos informa en una nota a pie de página, del lugar de redacción de la misma: La Bastilla, la prisión del sistema que se convierte en el lugar de la subversión a través de la escritura. Y es su deseo de defenderse de este arresto, injusto por lo demás, lo que le llevará a la creación del texto que nos ocupa.

Para este estudio vamos a basarnos en el cuento Le Président mystifié, texto que se genera como conflicto del yo-escritor con la realidad, entendida como statu-quo políticosocial y moral de la época.

Las razones que nos han llevado a la elección de dicho texto son varias, por una parte estaría el hecho de que no haya sido estudiado con anterioridad, pues estamos ante una obra olvidada por la crítica, que se ha tendido siempre a encasillar como uno de los textos menores dentro de la extensa producción de su autor, y que nos ha llegado junto con otras 
obras de idéntico corte, reunidas bajo el epígrafe «Historiettes, contes et flabliaux»!

Pero no obstante, y bajo la apariencia anodina del texto emerge la verdadera subversión sadiana, de forma más o menos abierta, recorriendo la práctica totalidad de las obras de Sade, como es la dura crítica a la Iglesia y a la Magistratura, convirtiendo sus escritos en verdaderas diatribas contra ambos estamentos.

Este carácter emergente en todas sus obras no es algo gratuito y exento de base, sino que encuentra su razón de ser en la propia vida del escritor, perseguido y encarcelado por los estamentos aludidos, las más de las veces de forma arbitraria. Uno de estos arrestos, y más concretamente el que ha provocado la situación que vive el autor en el momento de la escritura, aparece reflejado en nuestro texto, obra donde se conjuga perfectamente el más fino y delicioso humor provenzal, con los más despiadados y encarnizados ataques a sus verdugos. En el tex to asistimos a las desventuras burlescas de uno de los magistrados del parlamento de Aix-en-Provence, quienes en septiembre del 1772 condenaron a muerte a Sade de forma parcial y arbitraria ${ }^{2}$.

El autor se sirvió de este texto porque las críticas en él vertidas aparecen puestas en boca de alguien que estaría dentro del sistema, y lanzadas contra alguien que se encontraría fuera del mismo, ya que se trataría de un libertino, cúmulo de vicios morales. Estaríamos pues ante un caso en que las críticas no provocarían, al menos de forma aparente, la subversión del statu-quo, pero que al mismo tiempo son más clicaces.

Asistiremos en la obra, por otra parte, a la transposición al universo imaginario del tex to, del universo real del autor, entendiendo por éste último la suma de fechas, la alusión a personas de su entorno, y a la representación de los lugares por los que discurrió su vida; pues en la estructura anecdótica se plasma de forma velada y a veces enigmática, datos muy concretos de su biografía, y que parten desde su nacimiento, hasta la situación en que se encuentra en el momento presente.

Centrándonos en el tex to se observa de qué forma la anecdótica recoge un tema tópico en la historia de la literatura como es el matrimonio por imposición, pero no por conocido menos tratado, constituyendo dicho tema un mero marco, base para la fijación de la verdadera intencionalidad del escritor: la burla, el castigo y la humillación a la Magistratura, representada en la figura de Fontanis.

Este tema del castigo al estamento judicial constituye el motivo fundamental que llevará al yo a la redacción del texto. Esta intención del yo aparece puesta de manifiesto en los dos versos que encontramos al inicio del cuento y situados a modo de introducción:

1 Proyecto de escritura que SAIr: no llegó a realizar. La idea primitiva era recoger en un volumen su producción como cuentista, que comprendía unas cincuenta obras, y estarían dispuestas de modo que a una historia alegre sucediese una triste o dramática. Pero de ellas, sólo llegó a ver publicadas las obras «serías», en número de once, precedidas de las «Idées sur le roman», agrupado todo el conjunto bajo el epígrafe «Les Crimes de l'amour». Por lo que respecta al bloque en el que quedó recogida la obra que nos ocupa, éste no será publicado hasta 1926 por MAUIRICI: Ht:INF, crítico de SAIl:.

2 LF1.Y, G.: Sade (Editions Gallimard, 1972), pág. 97: «C'est le premier magistrat de provence (M. de la Tour, premier président du parlement d'Aix) qui admet quatre ans seulement plus tard l'excès de la condanation". 
«Oh fiez-vous à moi, je veux les célébrer si bien... que de vingt ans ils n'osent se montrer!»?

Donde queda puesta ya de manifiesto la ironía sadiana que va a recorrer todo el tex to.

La intencionalidad del autor queda igualmente puesta de manifiesto, como ya anunciábamos, en el propio título del cuento: Le Présidente mystifié, aunque el mismo aparece minimizado con respecto al tono que se adopta a lo largo del texto, dado que el vocablo «mystifier» significa «abuser de la crédulité de quelqu'un pour se moquer de lui», el presidente será burlado y engañado.

Será el marqués d'Olincourt quien encauce estos deseos de venganza del autor, él dirige y ordena como si de un director teatral se tratase; de su boca parten todas las críticas. Es por tanto este actante en quien Sade delega su defensa. Pero si atendemos a la crítica y burla que se hace en el texto, Sade no sólo persigue como objetivo la autodefensa, sino que este deseo conecta directamente con un violento ataque al estamento judicial desde su base: la procedencia social de sus miembros, el estar constituido por miembros de las profesiones más humildes y por gentes de la peor condición, que han ido ascendido progresivamente desde el punto de vista socioeconómico, hasta el punto de equipararse a la alta nobleza. Sade no tolerará nunca ser condenado por gentes que según él deberían estar encerradas. Aspecto éste que pone de manifiesto la conciencia aristocrática de Sade a pesar de sus simpatías por los principios revolucionarios.

Este objetivo del escritor, como ya hemos apuntado, no es algo que se manifieste en el tex to de forma clara a nivel de la estructura anecdótica, sino que es una idea latente que subyace bajo aquella, constituyendo un subtexto, una estructura profunda que corre paralela a la primera. Ambas estructuras encontrarán un punto de unión: Fontanis, constituyéndose este actante en intersección de ambas líneas, puesto que él es el magistrado de Aix-en-Provence (al que aludíamos con anterioridad en nuestra introducción) al mismo tiempo que es el novio impuesto a Mlle. de Téroze.

Llegados aquí debemos señalar que la materia anecdótica sobrepasaría el marco puramente tópico al constituir una transposición en el texto de un hecho real de la vida del autor, y más concretamente de su juventud: la imposición de su padre que le obligó a casarse por interés, con una mujer a la que no amaba, por pertenecer ésta a una importante familia de magistrados, estamento que poseía un poder socio económico inmenso, mayor aún que la alta nobleza, clase a la que pertenecía Sade.

La proyección del yo no se realiza de forma directa, sino a través de las reiteradas alusiones existentes en la estructura anecdótica, a un «gentilhomme» ${ }^{4}$ del que se nos dice que ha sido injustamente condenado, y al que todos tratan de defender. Para tal fin se hace alusión a las circunstancias que provocaron su encarcelamiento:

Sald, D.A.F.: Le Président mystifié en Otuvres complètes du marquis de Sade. (Société Nouvelle des Editions Pauvert, 1986), Tome II, pág. 89.

4 Este "gentilhombre» al que se alude es el propio autor, que en el momento en que escribe la obra se encuentra en la cárcel, como ya hemos afirmado en otro momento de nuestro estudio. 
«Tenez nous avons ici le juge de la terre de M. le Marquis qui était devenu fou à tel point qu'il n'y avait pas un jeune libertin de l'endroit s'amusant avec une fille, auquel ce coquin ne fît aussitôt un procès criminel, et le décret et la sentence et l'exil et toute les platitudes que ces drôles-là ont toujours dans la bouche» ${ }^{5}$.

«Rappelez surtout aux juges de Paris devant lesquels vous allez être obligé de comparaître, cette aventure fameuse de 1769 , où leur coeur bien plus ému de compassion pour le derrière flagellé d'une raccrocheuse que pour le peuple dont ils se disent les pères et qu'ils laissent pourtant mourir de faim, les détermina à faire un procès criminel à un jeune militaire qui revenant de sacrifier ses plus belles années au service de son prince, ne trouva d'autres lauriers au retour que l'humiliation preparée par la main des plus grands ennemis de cette patrie qu'il venait de défendre...» ${ }^{6}$.

«En 1772, un jeune homme de distinction de la province ayant voulu par une vengeance badine étriller une courtisane qui lui avait fait un mauvais présent, cet indigne butor fit de cette plaisanterie une affaire criminelle, il traita la chose de meurtre, d'empoisonnement, entraîna tous ses confrères à cette ridicule opinion, perdit le jeune homme, le ruina et le fit condammer par contumace à la mort, ne pouvant venir à bout de saisir sa personne»?

Estas tres citas no vienen sino a ilustrar nuestra afirmación. Las dos últimas constituyen alusiones a otros tantos escándalos que salpicaron la vida del autor, y cuya autoría condujo a Sade a prisión. Se trata de los célebres episodios conocidos como «Affaire d'Arcueil» y «Affaire de Marseille» respectivamente, recogidos ambos por Gilbert Lely en su biografía del escritor ${ }^{8}$.

En la primera de las citas se alude de forma general a la constante persecución de que siempre fue objeto el autor, convirtiéndose en blanco de todo tipo de acusaciones. Baste

SAIt,, D.A.F.: Op. cit., tomo II, pág. 106.

SAIr, D.A.F.: Op. cit., tomo II, pág. 126.

7 SADF, D.A.F.: Op. cit., tom0 II, pág. 124.

8 Let.Y, G.: Op. cit., pág. 8-9.

«Le 3 avril 1768, place des Victoires, il (Sade) s'adresse à une femme qui demande l'aumône, Rose

Keller; elle accepte de l'accompagner à sa «petite maison d'Arcueil». Il l'y fait se deshabiller, la flagelle à plusieurs reprises, puis l'enferme dans une chambre. La Keller s'évade, porte pleinte et obtient une indemnité énorme (...). M. de Sade n'est condamné qu'à une amende par la Grand Chambre du Parlement de Paris, cependant il reste détenu, d'ordre du roi, jusq'en novembre 1768 (...).

Le 27 juin 1772, de passage à Marseille, il se rend le matin avec son domestique Latour dans une chambre où quatre filles sont réunies. Flagelation reçue et infligée, futution, pédication, homoscxualité; l'une des filles, Mariane Laverne, goûte aux anis cantharidés que lui offre le marquis. Le soir, visite du libertin à une autre prostituée, Marguerite Coste, qui absorve tout le contenu de la bombonière de son client. Elle se trouve bientôt dans un tel état qu'on la croit empoisonné. Le marquis de Sade est condamné par la Chambre des vacations du parlement de Provence à la peine capitale, pour crimes d'empoisonnement et de sodomie; le 12 septembre, le contumace est exécuté en effigic sur la place des Prêcheurs, à Aix». 
decir como ejemplo que 27 años de su vida los pasó en prisión, y que tres regímenes políticos tan distintos-Absolutismo, Período revolucionario e Imperio-coincidieran en condenar a un mismo hombre: Sade.

Este «gentilhomme» sería la representación en el tex to de todos aquellos que han sido víctimas de las injusticias y atropellos del estamento judicial, constituyéndose por tal motivo, en fuerza propulsora del relato.

Esta presencia del autor se enmarcaría dentro de lo que hemos dado en llamar estructura profunda del relato, pues sólo tras el estudio de la biografía de Sade, podemos llegar a saber que el «jeune militaire» o el acusado por envenenamiento en Marsella no es otro que el propio autor.

Todo esto nos conduce a uno de los objetivos que nos planteábamos al inicio de nuestro estudio -y al cual me remito-: de qué manera se configura en el texto el universo real del autor, representación llevada a cabo en los dos niveles en los que se estructura el texto, y a los que ya hemos hecho mención: profundo y anecdótico; siendo en este último donde se desvela aquel a partir de la presencia del yo. Nivel que estudiaremos seguidamente y para ello vamos primeramente a descomponerlo en sus tres coordenadas constitutivas -espacial, temporal y actancial-centrándonos de manera espacial en ésta última, por ser en ella donde queda recogido, de forma especial, el objetivo primero de nuestro trabajo: estudiar de qué forma uno de los actantes se constituye en defensor último del escritor en este texto.

Vamos pues a hacer un recorrido por dichas coordenadas, tomando como punto de partida la coordenada espacial.

Los espacios anecdóticos que se nos muestran en el texto son la transposición al universo imaginario de espacios reales por los que discurrió la vida del autor, como señala Barthes en su célebre y siempre actual trabajo:

«... à Saint-Germain-des-Prés (...). Sade est né dans une chambre de l’hôtel de Conde (...); il a été baptisé à Saint-Sulpice; en 1777, sous lettre de cachet, c'est à l'hôtel de Danemark (...) que Sade est arrêté, c'est de là qu'on le conduit au donjon de Vincennes.

Au printemps de 1779, Sade étant emprisonné à Vincennes, on lui écrit que le verger de La Coste est éblouissant (...) espace autarcique, petite société complète dont il était le maître, source unique de ses revenus, lieu d'étude....".

El hotel del barón de Téroze representaría el hôtel de Condé, lugar donde nació Sade; el donjon de Vincennes aparecería simbolizado por el castillo de la dote de Mlle. de Téroze; la iglesia de Saint-Sulpice, en la que contraen matrimonio el magistrado y la joven, posee incluso el mismo nombre que aquella en la que fue bautizado, tiempo atrás,

" Barthes, R.: Sade, Fourier, Loyola (Seuil, Paris, 1971), pág. 177. 
nuestro escritor; y espacio en el que Fontanis nacerá a la vida, vida de víctima (lo que constituye una subversión completamente sadiana del bautismo). El lugar de reunión de los actantes en su conspiración contra Fontanis, representaría la «petite maison d'Arcueil», a la que Sade condujo a Rose Keller, la mendiga que posteriormente lo acusó de flagelación, dando lugar al célebre escándalo ya mencionado y que conocemos como «Affaire d'Arcueil»; y por último el castillo deI marqués d'Olincourt será la transposición en el texto de La Coste, propiedad del autor ${ }^{10}$.

Con esta representación de los espacios, Sade no hace sino proyectarse nuevamente en cl texto. Hará pasar a Fontanis, aunque en circunstancias diferentes, por todos aquellos lugares por los que se desarrolló su propia vida, desde su nacimiento, hasta su llegada a la Bastilla. El magistrado se constituye por tanto, en el doble invertido del autor. Ahora bien, con ello el escritor no sólo pretende llevarlo a la Bastilla (objetivo que finalmente consigue -en la ficción del texto-, al encerrar al personaje en el castillo de Mme. d'Olincourt, transposición en el texto de la prisión de Estado), sino que su objetivo final iría más alla: es la ejecución en efigie del magistrado, hecho que buscaría provocar su deshonra, como reo, del mismo modo que la provocó la condena del autor, ejecutado de idéntica forma en una plaza de Aix-en-Provence.

Todos estos edificios civiles y religiosos configuran el espacio de la mímesis, siendo por ello significantes de una parcela de la realidad, que queda limitada a la reproducción en el texto de un aspecto muy concreto de la vida del autor (la injusta condena de la que ha sido objeto y su posterior entrada en prisión, y a la recreación de todos los espacios que se circunscriben a esta época de su vida.

En un primer momento el texto se nos ofrece como imitación en parte de la realidad, pero tiende a crear su propio referente, articulándose pues como diégesis, desde el momento en que la realidad aparece representada y recreada de forma parcial, como es el hecho de representar únicamente como hábitat los espacios de la nobleza (castillos, hotel).

Estamos pues ante una lectura analógica de la realidad, en cuanto que lleva a la creación de un microcosmos único de un paisage interior, es decir, los espacios recreados son reales pero constituyen un fragmento de la realidad, pues ésta no se describe como totalidad, sino de forma parcial, descripción realizada en función del yo-escritor; y es esta modulación lo que lleva al texto a constituirse como diegético.

Tras esta prospección espacial nos detendremos a continuación, de forma breve, en el aspecto temporal del relato, con la sola intención de fijar el momento concreto de la redacción del texto, para pasar finalmente a la estructura actancial.

La coordenada temporal nos permite distinguir dos ejes temporales: por una parte nos

10 Espacio de especial significación para Sade, tierra de sus antepasados, situado en Provenza, región de especiales connotaciones históricas, literarias y artísticas. Es además un núcleo en el que lleva a cabo representaciones teatrales, además de espacio fundamental de sus escándalos libertinos. 
aparece el tiempo de la Historia, exterior al relato, que nos es facilitado por el mismo autor en la nota final del cuento, donde se nos informa de la fecha exacta de conclusión de la misma. El segundo eje estaría constituido por el tiempo referencial de la Historia, que corresponde al reinado de Louis XV y parte del reinado de Louis XVI, años que se corresponden con la época de juventud del escritor; este tiempo se nos muestra en el tex to de forma explícita.

Ambos ejes temporales vienen a demostrarnos una vez más, la transposición a la ficción, del universo real del autor, en este caso concreto, su juventud, y en ella, los datos que el considera relevantes para el objetivo final que se ha marcado: su defensa.

Nos centraremos a continuación en la coordenada actancial, aspecto en el que vamos a detenernos de manera especial, por constituir los personajes el eje central de nuestro estudio, como aglutinantes de toda la carga crítica del autor.

Ahora bien, esta proyección del yo sobre sus personajes no se globaliza sobre d'Olincourt de forma única y exclusiva aunque éste sea designado por el autor como su portavoz, como veremos más adelante.

La proyección del autor sobre sus personajes está presidida en todo momento por un carácter teatral -tomando este término desde la óptica del arte escénico-. Afïrmación en absoluto gratuita puesto que para Sade, la gran pasión de su vida era el teatro y todo lo referente a las costumbres de este arte; durante su vida mantuvo una lucha constante con el objetivo de poder representar sus piezas, hecho que se producirá durante su encierro en Charenton en los últimos años de su vida.

Este carácter teatral emerge de forma más o menos aparente en la práctica totalidad de sus obras. En nuestro texto, este matiz se advierte en la estructura misma de la obra, en la que ésta -un cuento- reproduce en su interior una pieza teatral de carácter tragicómico, cuyo tema es la burla y humillación de un magistrado; en la que los actores están constituidos por los mismos personajes del cuento (alguno de estos aparecerá incluso disfrazado para representar su papel de forma más pertinente); $y$ donde el director es al mismo tiempo actor: el marqués d'Olincourt, supeditado en última instancia a su creador: Sade.

Se da pues una inclusión de una obra dentro de otra, lo que muestra una perfecta conjunción narratividad-teatralidad. Pero dicha teatralidad no se limita en el relato exclusivamente a la reproducción dentro del texto narrativo de una obra dramática, sino que le lleva incluso a la representación del autor en el universo del texto, proyectándose sobre los distintos personajes a los que presta rasgos de su propia personalidad; proyección que se realiza de forma especial sobre d'Olincourt.

Ahora bien, esta teatralización no aparece de forma gratuita, sino que persigue un fin, que entronca de forma directa con el objetivo general de la obra: la humillación al magistrado, llevada a cabo no sólo por d'Olincourt, sino por todos los actantes de la narración.

Pasaremos pues a ver, como d'Olincourt se genera como actante principal, asumiendo así mismo la función de portavoz del autor como ya anunciábamos. 
Este actante se nos presenta en el tex to como cuñado de Mlle. de Téroze, la joven que se ve obligada al matrimonio con el magistrado, y será el deseo de evitar esta unión, el pretex to utilizado para lanzar todo tipo de ataques, críticas e insultos a Fontanis; críticas que se hacen extensivas a todo el estamento judicial, y que tendrán como objetivo final la defensa del escritor.

$\mathrm{Al}$ erigirse d'Olincourt en portavoz del autor, éste no duda en acudir a la Historia, efectuando un recorrido por todos los casos en los que la Justicia actuó de forma injusta, episodios que se remontan incluso a la Grecia de Pericles (aludiendo al juicio de la cortesana Friné) para pasar posteriormente a la época renacentista francesa, en la que Iglesia y Magistratura actuaron de forma conjunta en la masacre de Mérindol y Cabrières, hasta llegar de nuevo al siglo XVIII donde se alude a lo injusto del «Affaire Calas», poniendo Sade todos estos casos en boca de su personaje, y siempre con el mismo fin. Ahora bien, la alusión a todos estos casos no es gratuita, sino que vendría a demostrar como el encarcelamiento del autor no es un error aislado de la Magistratura, sino que sería un eslabón más de la larga cadena de atropellos de este Cuerpo.

Sade presta a esta actante bastantes clementos de su personalidad: del mismo modo que el escritor, d'Olincourt es marqués, noble de la «primera nobleza»; militar autoritario $^{11}$, desprecia la religión, la Magistratura; prefiere vivir retirado en su castillo como un señor feudal, a hacerlo en la corte (este deseo de resucitar el espíritu feudal en una época en la que los privilegios señoriales están desapareciendo, y las libertades van conquistando un lugar importante, encuentra su razón de ser en el intento, por parte de la nobleza, de recuperar un prestigio, un poder y unos privilegios que poco a poco son adquiridos por la potente burguesía, como clase que pasa a detentar el poder económico $)^{12}$; es significativo el hecho de que este actante, miembro de la alta nobleza, posea el título nobiliario de marqués, al igual que el escritor; $y$, dependiendo de las afirmaciones que aquel haga en cada momento, será citado como «d'Olincourt» o como «marqués».

Cuando aparece designado como «marquis», el autor se identifica plenamente con el personaje, dado que las palabras puestas en boca suya no van más allá de la plasmación de una mera idea personal.

«-Vous n'aimez pas la robe marquis?

- Je ne vous le cache pas, président, je n'aime que les états utiles» ${ }^{13}$.

1 Toda la obra de Sade aparece recorrida por una fuente ensoñación militar y gucrera, reflejada en la multitud de términos relativos al campo léxico de la milicia. Esta ensoñación llevará al escritor a concebir las actuaciones de sus personajes, incluso el sexo, como verdaderas acciones militares. En nuestro relato esta ensoñación es especialmente obsesiva, pues no olvidemos que los personajes se nos muestran como militares.

12 Esta ensoñación de poder de la nobleza no constituye en Sade, desde el punto de vista ideológico, un deseo de retroceso histórico a un período pasado en que la nobleza era todo poderosa y dueña de innumerables privilegios; sino que constituye más bien un elemento necesario en la anecdótica de multitud de sus obras. para situar episodios que sin este matiz serían inimaginables.

13 SADE, D.A.F.: Op. cit., pág. 118. 
Pero cuando aparece designado como d'Olincourt, el autor se desliga de su personaje, constituyendo este hecho una forma de no compromiso con él, pues considera muy fuertes las críticas y afirmaciones expresadas por este actante:

«Dites mieux, président, dites mieux, replica d'Olincourt qui commença à s'échauffer, dites que vous êtes des exécuteurs, d'insignes bourreaux qui, naturellemnt ennemis de l'État, n'avez de délices qu'à vous opposer à sa prospérité, qu'à placer des entraves à son bonheur, qu'à flétrir sa gloire et qu'à faire couler sans raison le sang précieux de ses sujets» ${ }^{14}$.

La defensa del autor realizada por d'Olincourt y la proyección del autor sobre éste es tal, que unidas a las críticas que lanzan contra Fontanis, llevarán a éste último a interrogarse sobre la posible existencia de lazos familiares entre d'Olincourt y el gentilhomme-el autor-:

«Ce d'Olincourt, il tient furieusement au procès de ce gentilhomme que nous jugeâmes l'an passé; il faut qu'il y ait là quelque alliance dont je ne me doutais pas...» ${ }^{15}$.

Si bien es cierto que d'Olincourt reune numerosos rasgos del autor, no lo es menos el hecho de que el autor preste numerosos rasgos a otros actantes, y de forma muy especial a Fontanis, a pesar de ser éste el blanco de todas las críticas e insultos del autor: Sade comparte con él su rechazo a los sentimientos (por ser éstos fuentes de dispersión del yo), el hecho de que una prostituta provoque su ruina moral y social; el ser rechazado por la sociedad e incluso por su propia familia, y que será además esta familia la que provoque su perdición total y encarcelamiento, pues su cuñado d'Olincourt ha obtenido del rey una pretendida «lettre de cachet».

Esta proyección del yo-escritor en el texto, y más concretamente en la figura de su enemigo, constituye a su vez la proyección de un rasgo de la personalidad del autor: su carácter sado-masoquista; sadismo en el reflejo de la multitud de castigos que inflige a Fontanis, y masoquismo en el hecho de proyectar su yo en su enemigo.

Antes de terminar con nuestro repaso a los actantes nos detendremos nuevamente en el estudio de la transposición al universo imaginario del texto, del universo real del autor, en este caso concreto, en la transposición a nivel de coordenada actancial, pues no debemos olvidar que los diferentes actantes del relato son otras tantas transposiciones al texto de distintas personas que rodearon al autor durante su vida:

El barón de Téroze representaría al padre del autor, por ser el representante del statuquo nobiliario, pero sobre todo por la imposición de boda hacia su hijo. Sade «revolucionario» se rebela contra este orden. 
Siguiendo esta lógica, Mme. de Téroze, madre de la joven Téroze, se presentaría como la madre del autor, pero aquella ni siquiera aparece en el texto, reflejo vacío de la ensoñación de la madre en las obras de Sade, hecho que iría acompañado de toda una misoginia y ataque a la mujer a lo largo de sus obras.

El conde d'Elbène, novio de la joven Téroze, miembro de la nobleza, está subordinado a d'Olincourt por el propio autor («... le jeune comte d'Elbène, colonel en second du regiment d'Olincourt...» ${ }^{3}$ ) a lo que se une su función de criado en la tragicomedia que se representa en el interior del relato, nos llevaría a considerarlo como la representación en el texto de Latour, el fiel criado de Sade, que ayudaba a su señor en la realización de todos sus deseos libertinos.

Dentro de esta transposición al texto de los personajes reales, debemos incluir a Fontanis como punto culminante: ya ha quedado puesto de manifiesto, como este actante representaría a uno de aquellos magistrados provenzales que condenaron a muerte al autor. Ahora bien, lo que realmente importa es ver como Fontanis sería la representación en el texto de la presidenta de Montreuil, suegra del autor; ella fue la responsable de las persecuciones de las que fue objeto su yerno durante la primera parte de su vida, y quien solicitó y obtuvo del rey la «lettre de cachet» que fue, como ya hemos afirmado, lo que provocó el encarcelamiento del escritor.

De aquí surgirá la rebelión de Sade a partir de una experiencia real de la injusticia de su época. Sade conoce la costumbre de encerar o exiliar a los libertinos para evitar el oprobio de la familia, ya que los prejuicios son enormes en esta época, pero no acepta él ensañamiento de su suegra, que le ha llevado a permanecer "sine die" en una torre, encerrado tras diecinueve puertas de hierro, recibiendo la luz del día por dos ventanucos, guarnecidos por una veintena de barrotes cada uno disponiendo durante diez o doce minutos al día de la compañía de un hombre que me trae la comida». (Carta del autor a Mme. de Sade, Vincennes, febrero de 1779).

Y sobre todo, siente como desmesurada la utilización de una «lettre de cachet», ya que «esos encarcelamientos arbitrarios e indefinidos no pueden caer, en el peor de los casos, más que sobre los agentes públicos muy secretos de los asuntos de Estado, cuando prevarican, o sobre aquellos cuya pluma o cuya lengua es demasiado indiscreta» ${ }^{16}$.

Sade, además, no se siente en absoluto culpable: «El señor de Sade ha hecho lo que hace todo el mundo. Las jóvenes que ha frecuentado estaban ya completamente depravadas o le eran aportadas por una comadres. Por lo tanto, no se trata de ninguna seducción. Sin embargo, se castiga y se hace sufrir al señor de Sade como si fuera culpable de los crímenes más negros (...). No soy culpable más que de puro y simple libertinaje, tal y como lo practican todos los hombres en mayor o menor razón de su mayor o menor tempera-

16. Mercier, L.S.: Tableau de Paris (Paris, Librairie de la Bibliothèque Nationale, 1884-1888), tomo II, pág. 27. 
mento o de la mayor o menor inclinación hacia eso que hayan podido recibir de la naturaleza». (Carta del autor a Mme. de Sade, Vincennes, febrero de 1781).

Es pues posible que todas las obras pertenecientes a este período, entre las que se incluye nuestro texto objeto de estudio, fueran, además de un modo de agresión contra un pacto social que había hecho de él su víctima, una especie de catarsis para liberarse de su angustia ${ }^{17}$.

Digamos para terminar que nuestro texto ha sido la solución de dos conflictos que se nos plantearon desde el inicio del mismo, uno a nivel de estructura anecdótica (la historia de Mlle. de Téroze) y otro a nivel de estructura profunda (el yo frente al statu quo) en los versos introductorios de la novela.

Ambos conflictos se generan por dos actantes considerados como colectivos, en cuanto que representantes de todas aquellas víctimas tanto del estamento judicial, como de la autoridad paterna. Ahora bien la salida que se les da a cada uno de ellos es diferente en cada caso. A nivel anecdótico Mlle. de Téroze verá realizado su deseo: casarse con el hombre que realmente ama; mientras que a nivel profundo, Sade conseguirá hacer una crítica, golpear al statu-quo que se ha aliado contra él.

Los dos conflictos mencionados, son conflictos del yo-autor, y como tales, se generan como conflictos en la Historia, pues es esta coordenada la que les sirve de justificación y base, tanto a nivel anecdótico como profundo.

El texto se ha generado como diégesis en función de la escritura, por ampliación exagerada de la información. El tex to como discurso no ha cubierto todos los espacios del campo mimético de referencia, y la ha recreado en diferentes niveles, poniendo en ellas el énfasis de la representación, y como tal, ha sido modulada por el escritor. Todo ello con un objetivo marcado desde el inicio por el autor, como ya hemos afirmado: su defensa.

17 Y no sólo en estas obras, sino que este rechazo a la sociedad y a sus dirigentes que lo han encarcelado es una constante en toda su producción literaria. 